\title{
Effects of Nitride on the Tribological Properties of the Low Carbon Alloy Steel
}

\author{
Yuh-Ping Chang, ${ }^{1}$ Jin-Chi Wang, ${ }^{1}$ Jeng-Haur Horng, ${ }^{2}$ \\ Li-Ming Chu, ${ }^{3}$ and Yih-Chyun Hwang ${ }^{4}$ \\ ${ }^{1}$ Department of Mechanical Engineering, Kun Shan University, Tainan 710, Taiwan \\ ${ }^{2}$ Department of Power Mechanical Engineering, National Formosa University, Yunlin 632, Taiwan \\ ${ }^{3}$ Department of Mechanical and Automation Engineering, I-Shou University, Kaohsiung 840, Taiwan \\ ${ }^{4}$ Hiwin Technologies Corp., Taichung 40707, Taiwan
}

Correspondence should be addressed to Yuh-Ping Chang; ypc0318@mail.ksu.edu.tw

Received 15 September 2013; Accepted 2 November 2013

Academic Editor: Shoou-Jinn Chang

Copyright (c) 2013 Yuh-Ping Chang et al. This is an open access article distributed under the Creative Commons Attribution License, which permits unrestricted use, distribution, and reproduction in any medium, provided the original work is properly cited.

\begin{abstract}
The technology of composite heat treatment is used popularly for low friction and wear resistance of drive elements. A large number of papers about the heat treatment technology had been proposed. Especially, the nitride treatment has been used widely for the purpose of wear resistance and low friction in the industry. Therefore, the self-developed vertical ball/disk friction tester with the measurement system was used to study the effects of nitride on the tribological properties of the low carbon alloy steel-SCM415in this study. The experiments were conducted under dry and severe wear conditions. The variations of friction coefficient and surface magnetization were simultaneously recorded during dynamic friction process. After each test, the microstructures of the wear particles were observed and analyzed under a SEM, and the depth of wear track is measured by means of a surface tester. According to the experimental results, the wear resistance of the specimens with carburizing-nitride is significantly larger than the case of nitride-carburizing. Moreover, the surface magnetization was especially larger for the case of nitride-carburizing. As a result, the wear particles always stay in the interfaces and the wear mechanism becomes complex. Therefore, it is necessary to put nitride after carburizing for the composite heat treatments.
\end{abstract}

\section{Introduction}

The performance of high quality and high accuracy is very important for the high accurate mechanical engineering. Hence, the drive elements play an important role when it was used in the actuator of the machine. Moreover, the high performance of low friction and wear resistance for drive elements is very important for the actuator. In order to achieve the above goal, the technology of composite heat treatment is attracted recently for the industry $[1,2]$.

A large number of papers about the composite heat treatment technology had been proposed [3,4]. Especially, the nitride treatment has been used widely for the purpose of wear-resistance and long fatigue life in the industry $[5,6]$. The tool steels containing $\mathrm{Al}$ or $\mathrm{Cr}$ by the nitride treatment are considered as a wise method for improving the surface hardness and the strength near the middle of the materials [7]. Therefore, the nitride treatment is always used to make surface hardening and improve wear resistance, fatigue life, and corrosion resistance for the tool steels $[8,9]$.

Since the authors had experimentally studied the tribological properties of the pair of iron with the carbon steels in depth [10-13], the knowledge is applied and adapted to the study of using continuous variation of friction coefficient for monitoring the tribological properties of the low carbon alloy steel in this paper. Therefore, the low friction and wear resistance for the carburizing steels of drive elements (such as SCM415) with nitride treatment are further investigated. Based on the results, the effects of different nitride treatments on the steels can be clarified. Besides, the purpose of better quality and faster product speed for the high accurate mechanical engineering can then be obtained. 


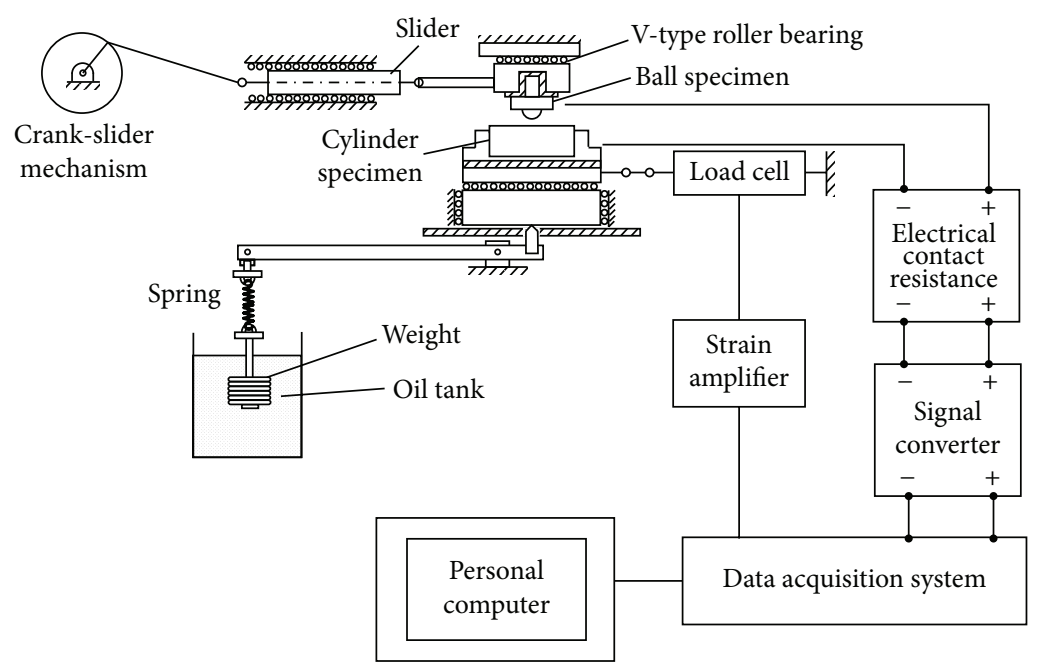

FIGURE 1: The reciprocating friction tester with the measuring systems.

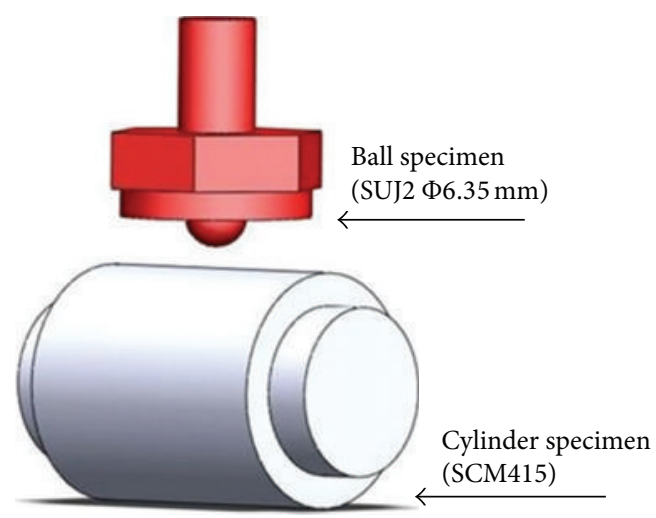

Figure 2: The size and shape of the ball and the cylinder.

\section{Experimental Apparatus and Procedures}

2.1. Experimental Apparatus. The experiments were conducted on a reciprocating friction tester with the measuring systems shown in Figure 1. A crank-slider mechanism was used in this reciprocating friction tester. The ball specimen was fixed to the carriage, which reciprocated along a $\mathrm{V}$ type roller bearing with an adjustable stroke via the length of the crank. In this study, the stroke of the crank-slider mechanism was set to $6 \mathrm{~mm}$. The stationary cylinder specimen was placed on a rest, supported by the $\mathrm{V}$ type roller bearing. A load cell was attached to the rest for measuring the friction coefficient between the ball and cylinder specimens. Consequently, the friction coefficient between the pin and plate specimens can be measured easily. A normal load was applied to the ball specimen through the cylinder specimen and aligned using a level rule. Furthermore, in order to avoid the impact effect and to remain the complete contact between the specimens during the friction process, a softer spring $(k=0.17 \mathrm{~N} / \mathrm{mm})$ with an oil damper $(c=1.04 \mathrm{Ns} / \mathrm{m})$ was installed as part of the loading system.
TABLE 1: Compositions of SCM415.

\begin{tabular}{lcccc}
\hline \multicolumn{5}{c}{ SCM415 wt\% } \\
\hline $\mathrm{C}$ & $\mathrm{Si}$ & $\mathrm{Mn}$ & $\mathrm{P}$ & $\mathrm{S}$ \\
$0.13 \sim 0.18$ & $0.15 \sim 0.35$ & $0.6 \sim 0.85$ & $\leqq 0.03$ & $\leqq 0.03$ \\
$\mathrm{Cr}$ & $\mathrm{Cu}$ & $\mathrm{Mo}$ & $\mathrm{Ni}$ & \\
$0.9 \sim 1.2$ & $\leqq 0.3$ & $0.15 \sim 0.25$ & $\leqq 0.25$ & \\
\hline
\end{tabular}

TABLE 2: Surface hardness of SCM415 with different composite heat treatments.

\begin{tabular}{lc}
\hline Composite heat treatments & Surface hardness (HRC) \\
\hline Carburizing-tempering & 66.1 \\
Nitride-carburizing-tempering & 65.8 \\
Carburizing-nitride & 42.8 \\
\hline
\end{tabular}

In Figure 1, the response time is less than $1 \mathrm{~ms}$ with the accuracy of $0.1 \%$ full scale. During the reciprocating friction process, the friction coefficient between the contacting specimens was derived from the voltage signal from the load cell and was recorded simultaneously by a data acquisition system. The signals were then fed to a personal computer for data analysis.

2.2. Test Specimens. In order to simulate the operating conditions of the drive elements (such as Ball Screws), the test specimens are arranged as ball/cylinder. The ball specimens were made of SUJ2. Besides, the cylinder specimens were made of SCM415. Moreover, the cylinder specimens had been conducted with the different composite heat treatments before the friction tests. The specimens are shown in Figure 2 and their material properties are given in Table 1. Moreover, the surface hardness of the cylinder specimens is shown in Table 2 .

2.3. Experimental Procedures. Prior to each friction test the specimens were cleaned with acetone in an ultrasonic cleaner 
Carburizing-tempering

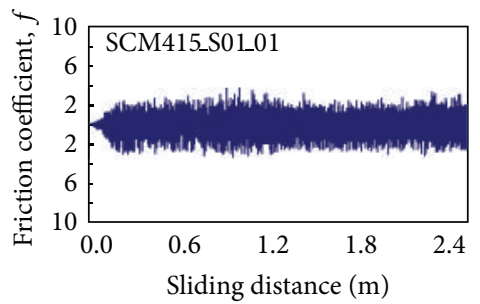

(a)

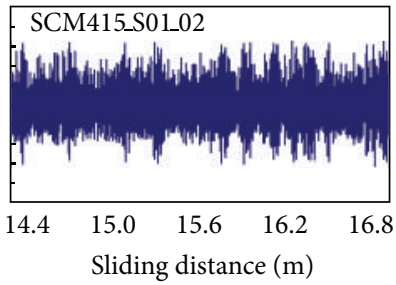

(b)

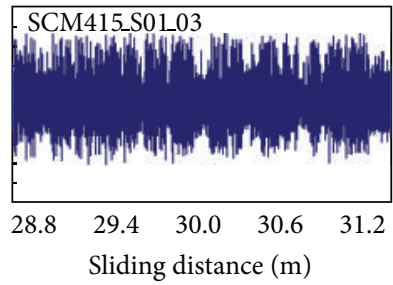

(c)

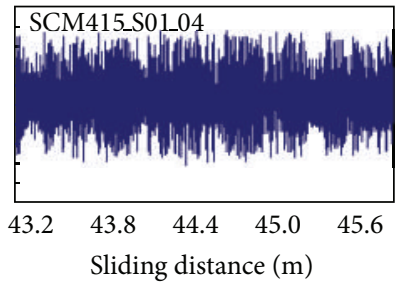

(d)

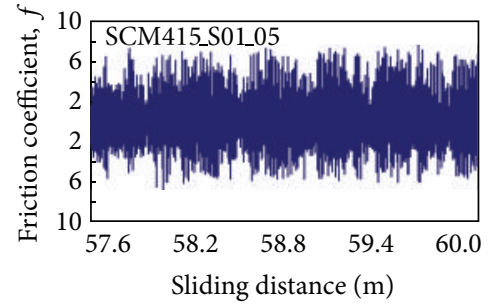

(e)

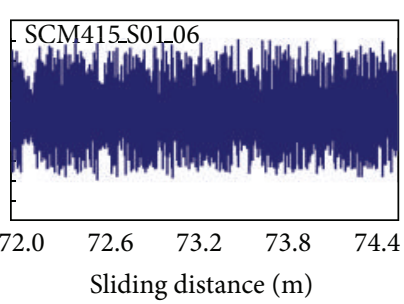

(f)

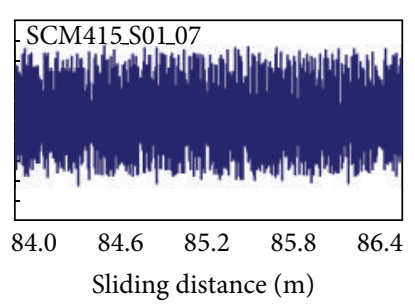

(g)

FIGURE 3: The typical variations of friction coefficient for SCM415 with carburizing-tempering.

before securely locked in position in the tester. The location and tightness between the ball and the cylinder interface were of paramount importance to ensure experimental accuracy. When the crank rotated clockwise at a set speed (cpm, cycles per minutes), the ball specimen reciprocated as a normal load was gradually applied to the interface of the specimens.

In this study, the reciprocating speed was fixed at $400 \mathrm{cpm}$ (or the average speed of the ball specimen $\mathrm{Va}=80 \mathrm{~mm} / \mathrm{s}$ ) and the normal loads were set as $50 \mathrm{~N}$. The dynamic variations of friction coefficient were measured during each test. After each test, the wear particles were examined under a SEM. The depth of wear track is measured by means of a surface tester. The response time of the measuring system was less than $1 \mathrm{~ms}$ and the accuracy was $0.1 \%$ full scale.

All tests were carried out under dry friction condition. The average room temperature for the test was $23 \pm 2^{\circ} \mathrm{C}$, and the average relative humidity was $65 \pm 5 \%$.

\section{Results and Discussions}

Figure 3 shows the typical variations of friction coefficient with sliding distance produced by the SUJ2 ball sliding on the SCM415 with carburizing-tempering. It is seen from this figure that the average friction coefficient is about 0.65 during the sliding distance of $0 \sim 2.4 \mathrm{~m}$. It gradually increases after the sliding distance of $14.4 \mathrm{~m}$. This indicates that the oxide film had been broken. Moreover, the friction coefficient significantly decreases after the sliding distance of $43.2 \mathrm{~m}$. It can be reasonably explained by that the wear particles play the roller role.

The typical variations of friction coefficient with sliding distance produced by the SUJ2 ball sliding on the SCM415 with nitride-carburizing-tempering are shown in Figure 4 . The average friction coefficient is about 0.65 during the sliding distance of $0 \sim 2.4 \mathrm{~m}$. It gradually increases after the sliding distance of $14.4 \mathrm{~m}$. Moreover, the friction coefficient significantly increases after the sliding distance of $45 \mathrm{~m}$. It can be reasonably explained by that the wear mechanism transfer to severe.

Figure 5 shows the typical variations of friction coefficient with sliding distance produced by the SUJ2 ball sliding on the SCM415 with carburizing-nitride. It is seen from this figure that the average friction coefficient is only 0.53 during the sliding distance of $0 \sim 2.4 \mathrm{~m}$ even when its surface hardness is the smallest. It gradually increases after the sliding distance of $14.4 \mathrm{~m}$. Moreover, the friction coefficient significantly increases after the sliding distance of $45 \mathrm{~m}$.

According to the above results, the friction coefficient of the specimen with carburizing-nitride is smaller than the other cases.

Representative metallograph and microstructures of surface for SCM415 with different composite heat treatments are shown in Figures 6-8. It is seen from Figure 6 that the film of the carburizing-tempering is about $0.09 \mathrm{~mm}$. Figure 7 shows that the film of the nitride-carburizing is only about $0.006 \mathrm{~mm}$. Moreover, the color is golden. On the other hand, the film of the carburizing-nitride is about $0.008 \mathrm{~mm}$. The color is white as shown in Figure 8.

From the above results, the films of nitride-carburizing and carburizing-nitride are too thin to support the higher loads. Therefore, the wear resistance is not significant for them in this study.

Figure 9 shows the SEM micrographs of wear particle for SCM415 with carburizing-tempering. It is seen from this figure that $30 \sim 40 \%$ of the wear particles are larger than $5 \mu \mathrm{m}$ order. The size of the larger wear particles reaches $100 \mu \mathrm{m}$ order.

Figure 10 shows the SEM micrographs of wear particle for SCM415 with nitride-carburizing-tempering. The size of the 


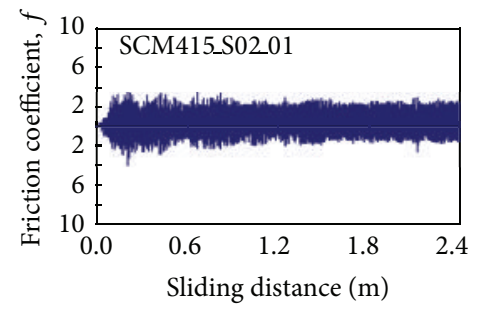

(a)

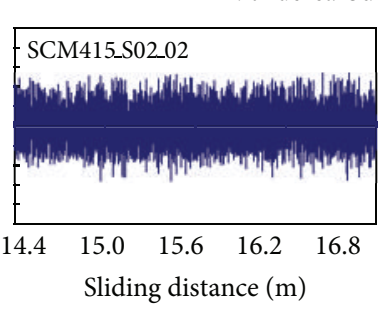

(b)

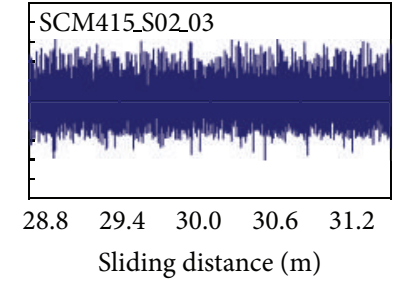

(c)

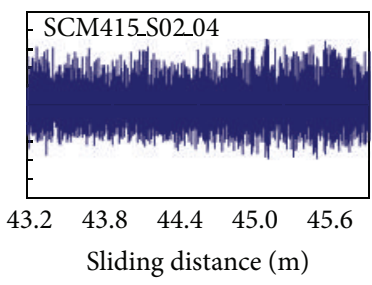

(d)

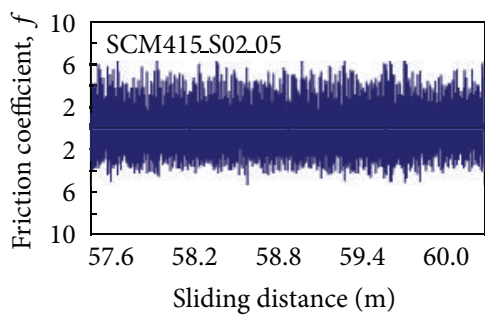

(e)

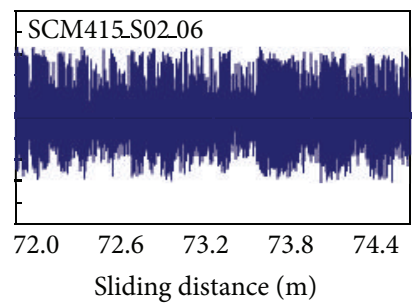

(f)

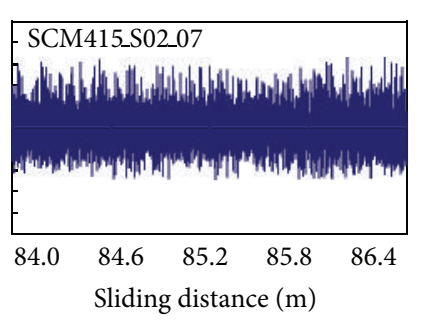

(g)

FIGURE 4: The typical variations of friction coefficient for SCM415 with nitride-carburizing-tempering.

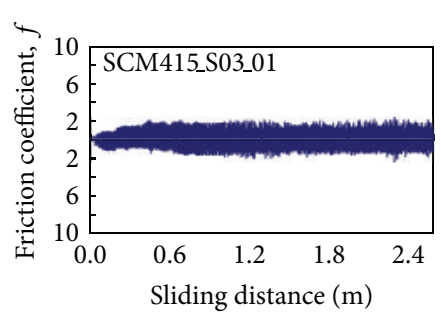

(a)

Carburizing-nitride

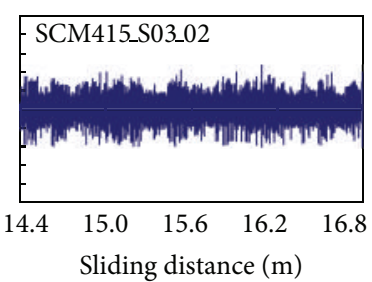

(b)

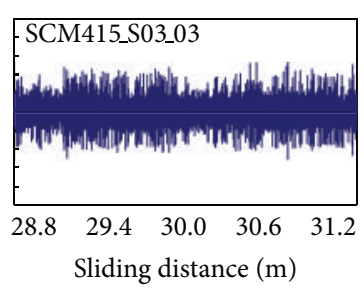

(c)

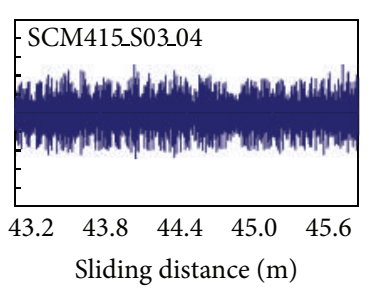

(d)

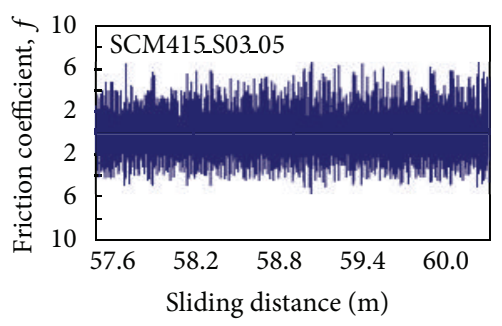

(e)

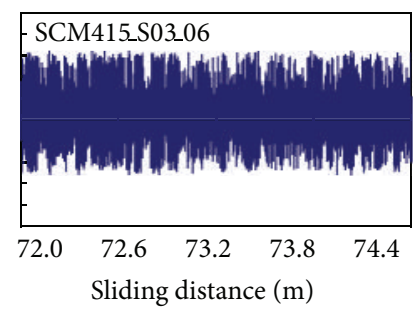

(f)

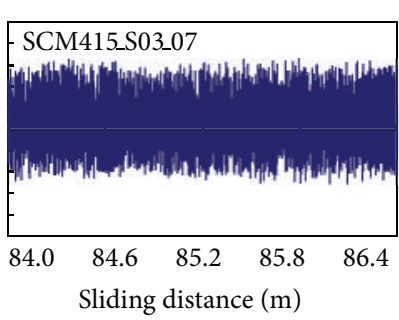

(g)

FIGURE 5: The typical variations of friction coefficient for SCM415 with carburizing-nitride.

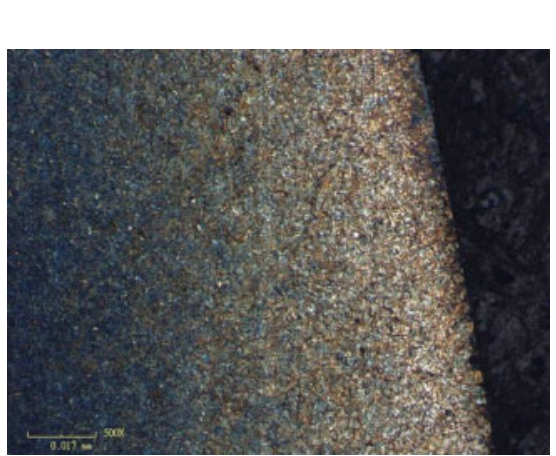

$\times 100$

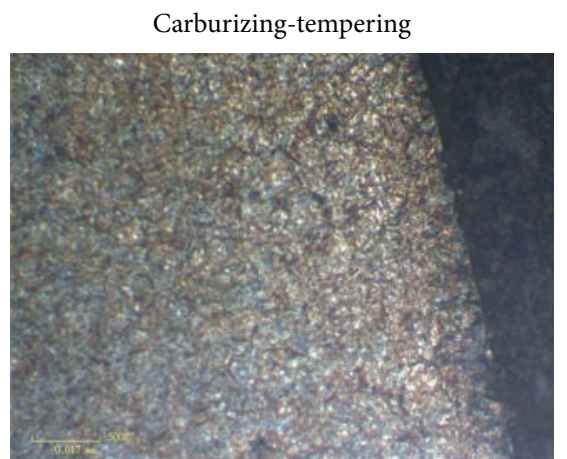

$\times 200$

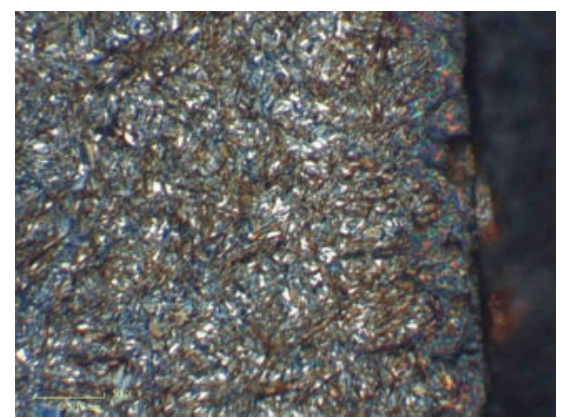

$\times 500$

FIGURE 6: Representative metallograph and microstructures of surface for SCM415 with carburizing-tempering. 
Nitride-carburizing-tempering

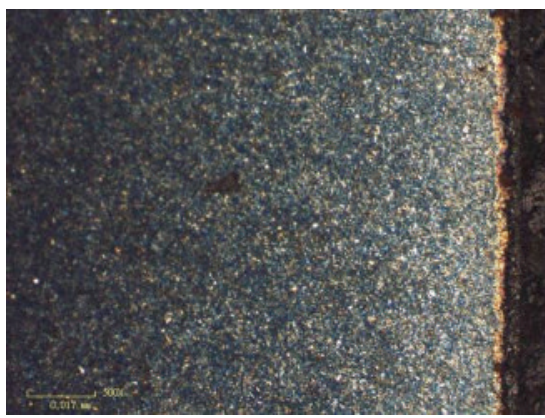

$\times 100$

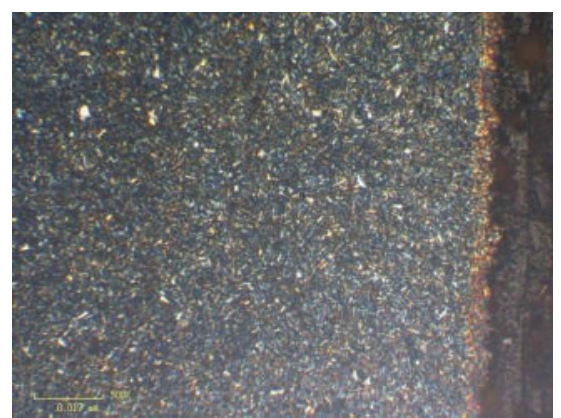

$\times 200$

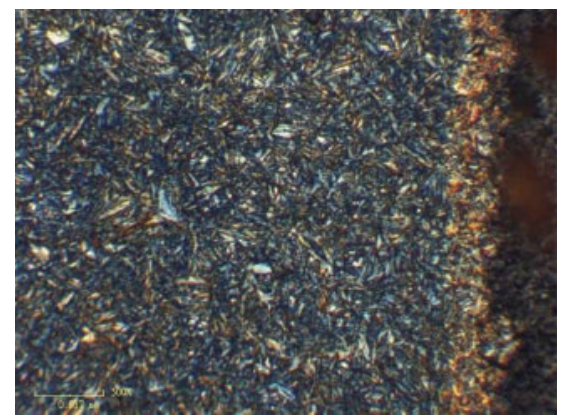

$\times 500$

FIGURE 7: Representative metallograph and microstructures of surface for SCM415 with nitride-carburizing-tempering.

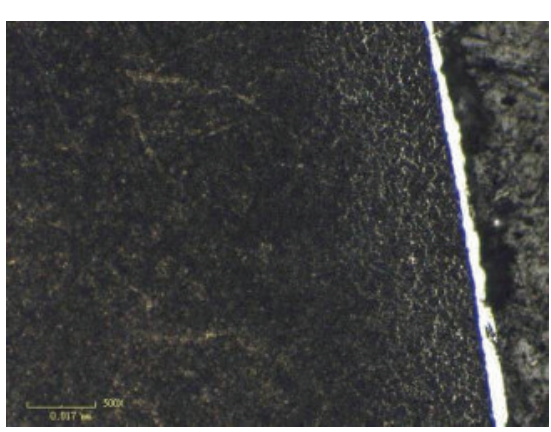

$\times 100$

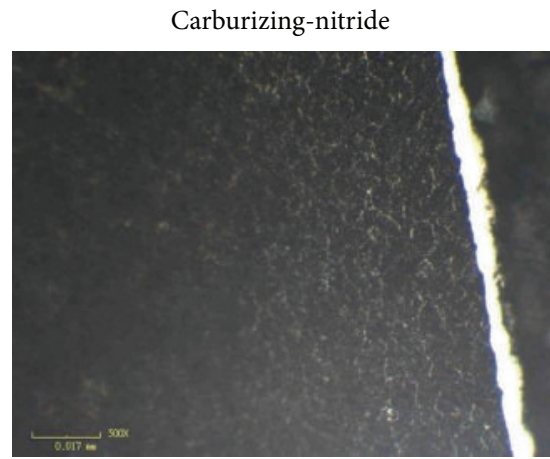

$\times 200$

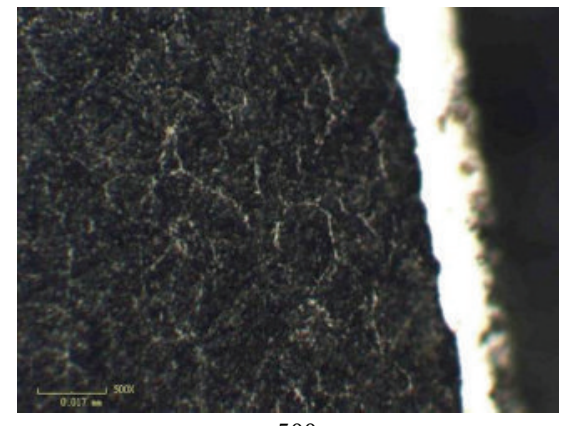

$\times 500$

FIGURE 8: Representative metallograph and microstructures of surface for SCM415 with carburizing-nitride.

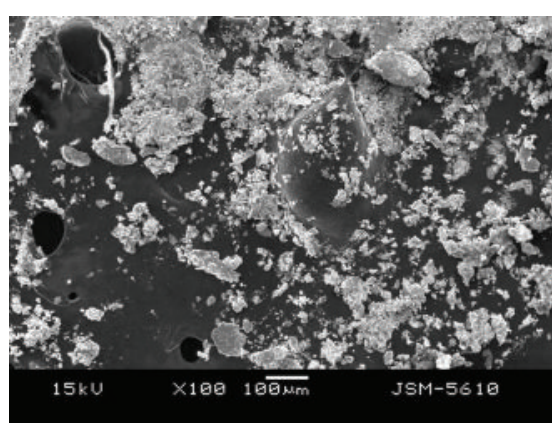

$\times 100$

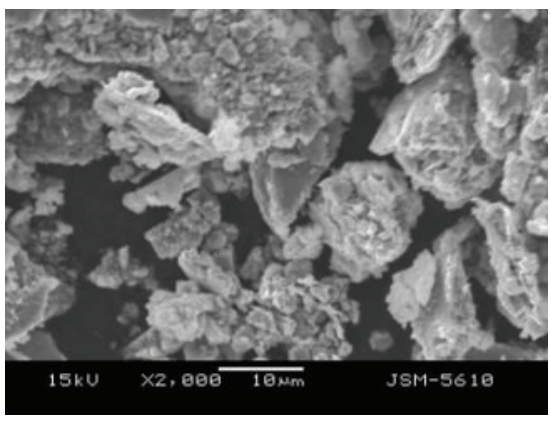

$\times 2000$
Carburizing-tempering

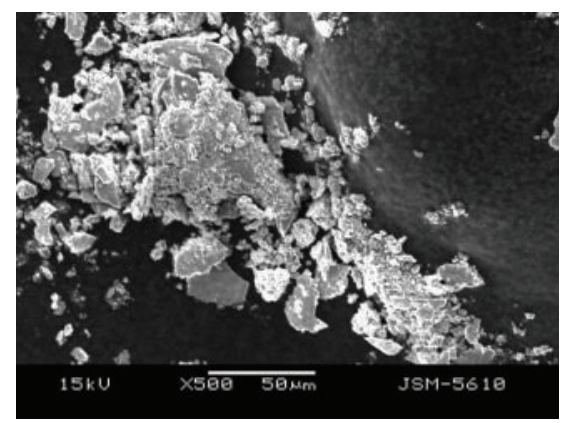

$\times 500$

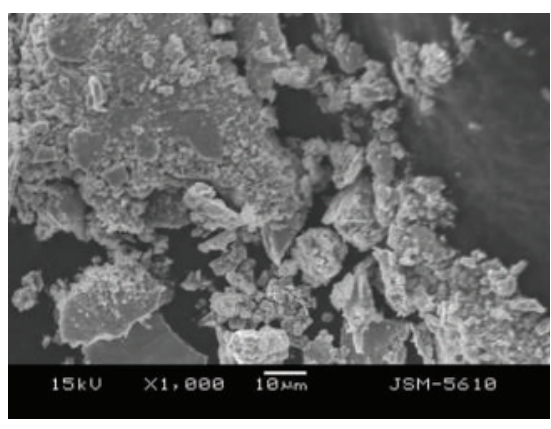

$\times 1000$

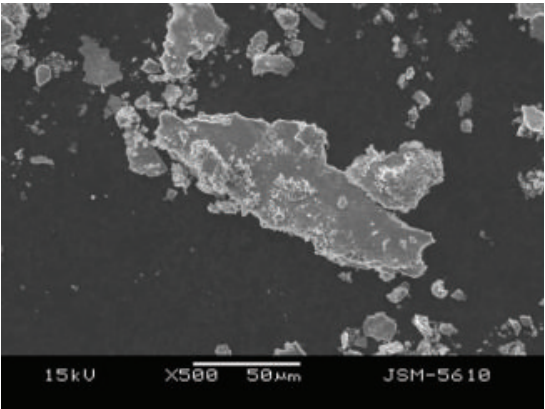

$\times 500 \_1$

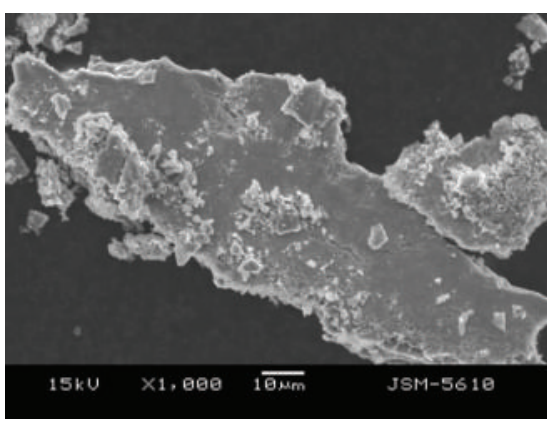

$\times 1000 \_1$

FIGURE 9: Representative SEM micrographs of wear particle for SCM415 with carburizing-tempering. 


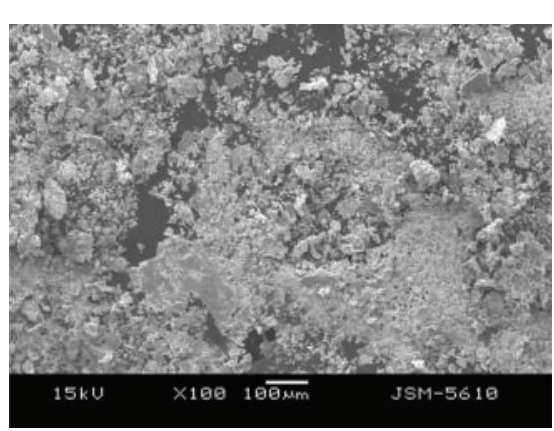

$\times 100$

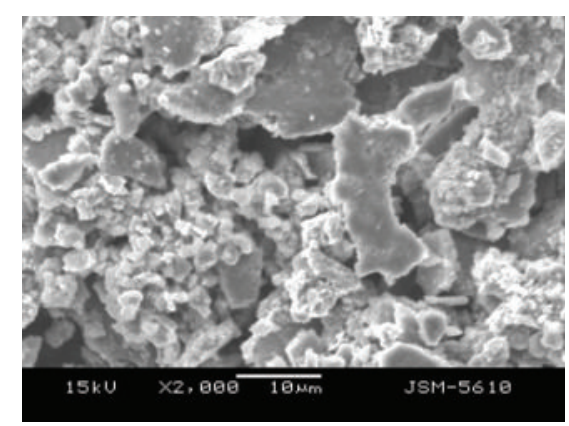

$\times 2000$

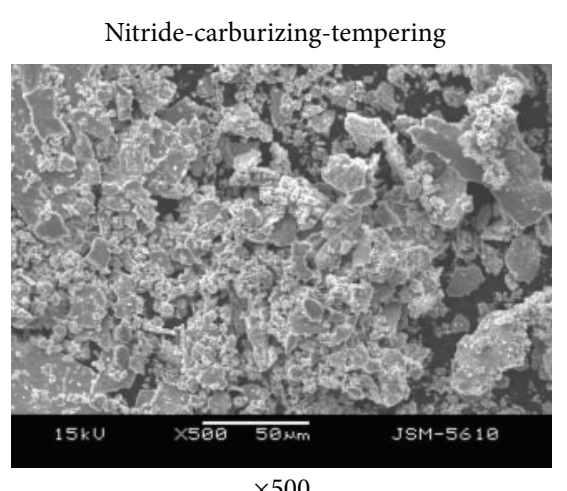

$\times 500$

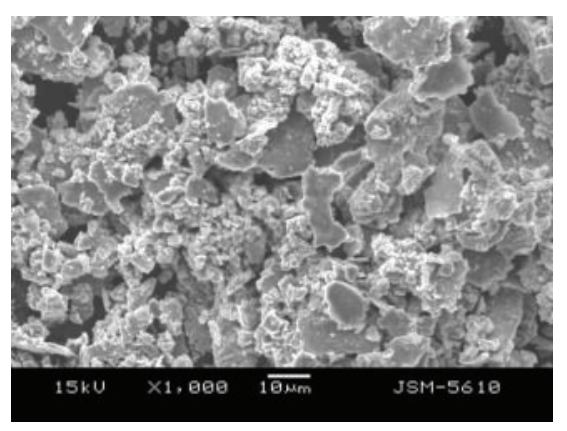

$\times 1000$

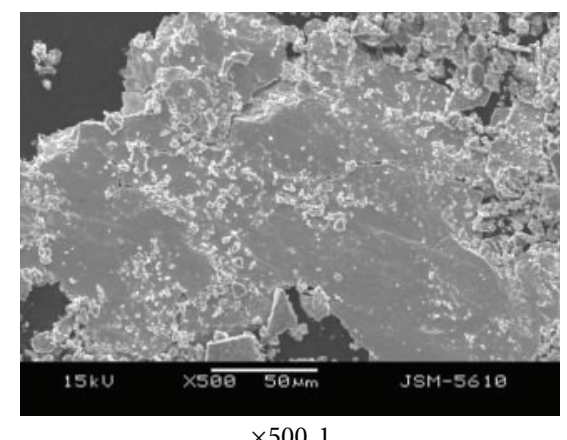

$\times 500 \_1$

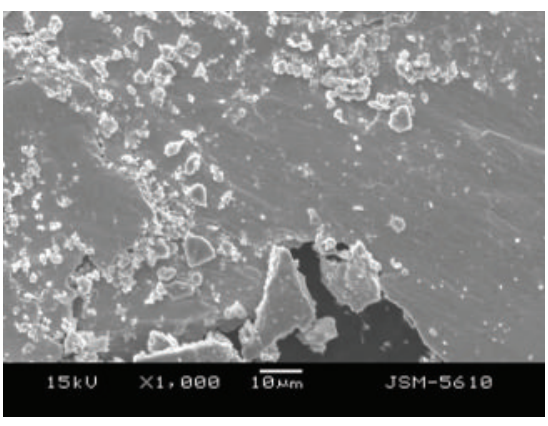

$\times 1000 \_1$

FIGURE 10: Representative SEM micrographs of wear particle for SCM415 with nitride-carburizing-tempering.

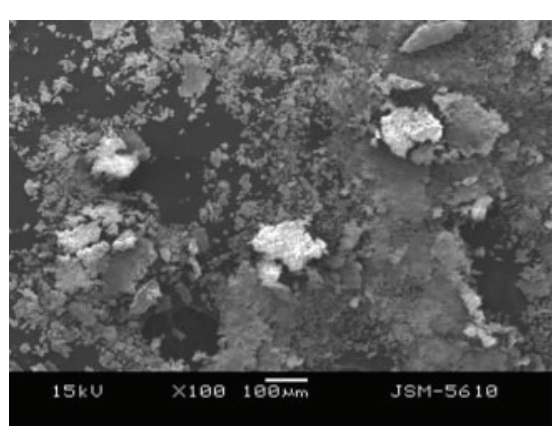

$\times 100$

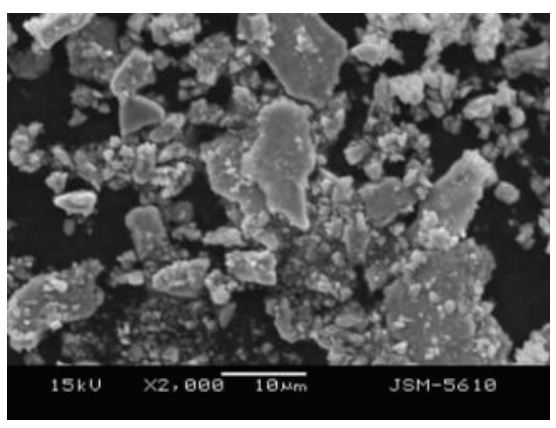

$\times 2000$

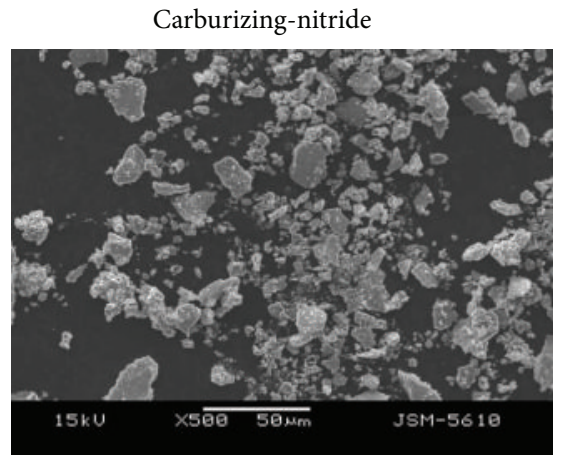

$\times 500$

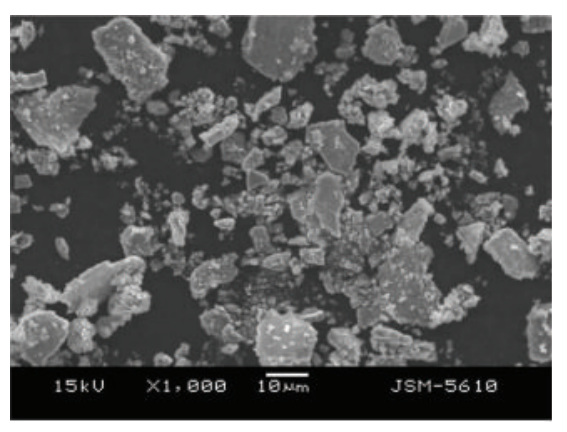

$\times 1000$

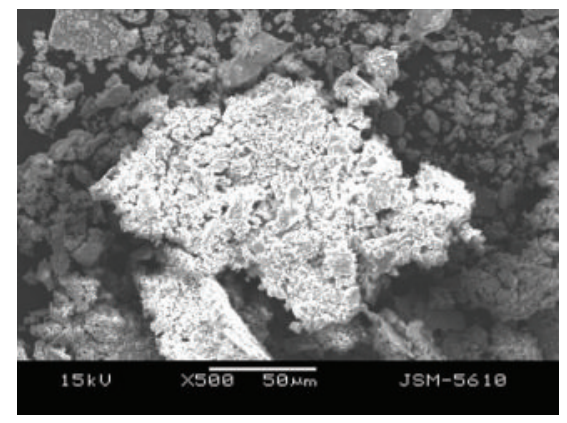

$\times 500 \_1$

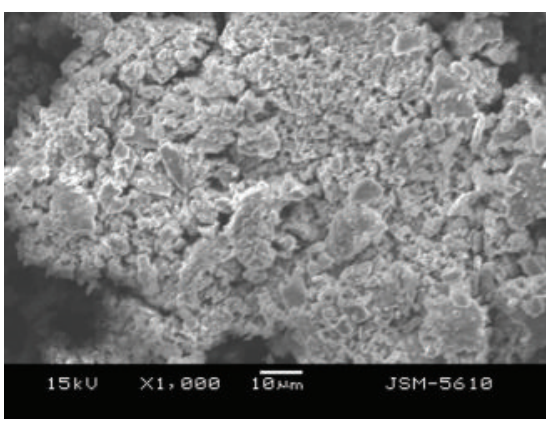

$\times 1000 \_1$

FIGURE 11: Representative SEM micrographs of wear particle for SCM415 with carburizing-nitride. 

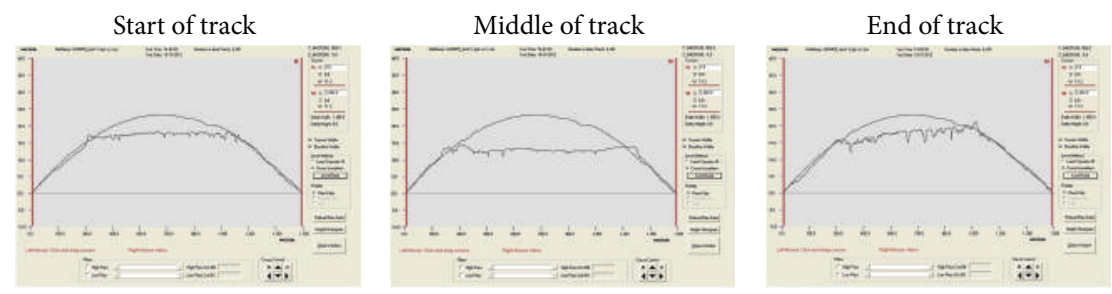

(a)
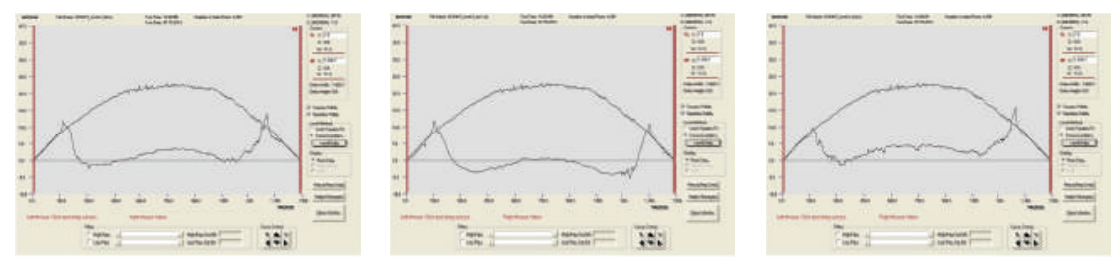

(b)
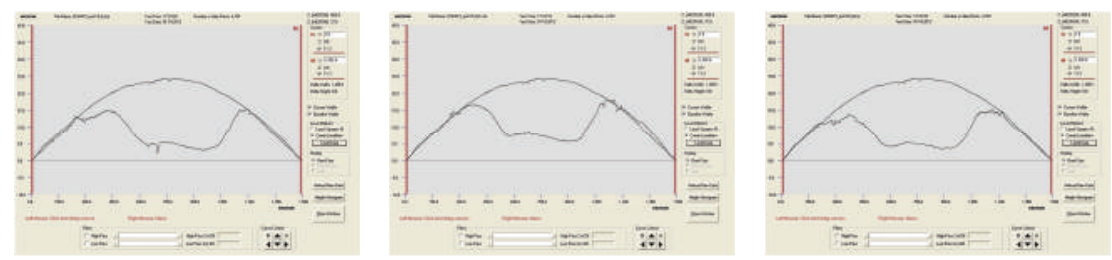

(c)

FIGURE 12: (a) Carburizing-tempering: the wear profile for the SCM415 cylinder. (b) Nitride-carburizing-tempering: the wear profile for the SCM415 cylinder. (c) Carburizing-nitride: the wear profile for the SCM415 cylinder.

larger wear particles is over $100 \mu \mathrm{m}$ order. Moreover, the wear particles are countless and highly concentrated. By a gauss meter, it showed that the surface magnetization was especially larger.

Representative SEM micrographs of wear particle for SCM415 with carburizing-nitride are shown in Figure 11. It is seen from this figure that $50 \sim 60 \%$ of the wear particles are only several $\mu \mathrm{m}$ order. The size of the larger wear particles is about 10 20 $\mu \mathrm{m}$.

Therefore, the surface magnetization was especially larger for the case of nitride-carburizing. As a result, the wear particles always stay in the interfaces and the wear mechanism becomes complex. Moreover, the amount of wear particle for SCM415 with nitride-carburizing-tempering or carburizingnitride are significantly larger, that is, severe wear; this can be reasonably explained by the results shown in Figures 6-8. On the other hand, the wear particles are smaller and the wear mechanism is mild for SCM415 with carburizing-nitride. Therefore, it is necessary to put nitride after carburizing for the consideration of wear resistance and low surface magnetization.

Figures 12(a)-12(c) show the wear profile for the SCM415 specimens. It is seen from this figure that the depth of the wear track is only $10.3 \mu \mathrm{m}$ for SCM415 with carburizingtempering. However, the depth of the wear track can reach $21.5 \mu \mathrm{m}$ for SCM415 with nitride-carburizing-tempering. Moreover, the depth of the wear track is about $18.2 \mu \mathrm{m}$ for SCM415 with carburizing-nitride. Therefore, the wear resistance of the specimens with carburizing-tempering is significantly larger. Moreover, the wear-resistance of the specimens with carburizing-nitride is larger than the case of nitride-carburizing-tempering.

\section{Conclusions}

The effects of nitride on the tribological properties of the low carbon alloy steel-SCM415-have been investigated. From the experimental results and the SEM observations of the wear particles, the following conclusions have been drawn.

(1) The friction coefficient of the specimen with carburizing-nitride is smaller than the other two cases.

(2) The film of the carburizing-tempering is significantly larger. This is the reason that the wear-resistance of the specimens with carburizing-tempering is larger than the other cases. Moreover, the wear-resistance of the specimens with carburizing-nitride is larger than the case of nitride-carburizing.

(3) The surface magnetization was especially larger for the case of nitride-carburizing. As a result, the wear particles always stay in the interfaces and the wear mechanism becomes severe and complex.

(4) It is necessary to arrange nitride after carburizing for the consideration of low friction, wear resistance, and low surface magnetization. 


\section{Conflict of Interests}

The authors declare that there is no conflict of interests regarding the publication of this paper.

\section{Acknowledgment}

The authors would like to express their appreciation to the National Science Council in Taiwan, R.O.C., for their financial support under Grant nos. NSC 101-2221-E-168-012 and NSC 102-2622-E-150-002-CC2.

\section{References}

[1] W. D. Callister, Material Science, Engineering: An Introduction, Wiley, New York, NY, USA, 3rd edition, 1994.

[2] K. E. Thelning, Steel and Its Heat Treatment, Bofors Handbook, 1975.

[3] D. H. Huang and G. Thomas, "Structure and mechanical properties of tempered martensite and lower bainite in $\mathrm{Fe}-\mathrm{Ni}$ Mn-C steels," Metallurgical Transactions, vol. 2, no. 6, pp. 1587$1598,1971$.

[4] A. M. Nasreldin, M. M. Ghoneim, F. H. Hammad, R. L. Klueh, and R. K. Nanstad, "Effect of tempering on the toughness of a Cr-Mo bainitic steel," Journal of Materials Engineering and Performance, vol. 2, no. 3, pp. 413-420, 1993.

[5] J. Guodong and H. Maolin, "Research on overheat hardening technology for 5CrMnMo steel," Material \& Heat Treatment, pp. 74-75, 2008.

[6] P. Clayton and R. Devanathan, "Rolling/sliding wear behavior of a chromium-molybdenum rail steel in pearlitic and bainitic conditions," Wear, vol. 156, no. 1, pp. 121-131, 1992.

[7] Z. Canxu, Z. Li, D. Yi, and M. Liqun, Effect of MiddleTemperature Heat-Treatment on Microstructure and Tensile Strength of Ferritic Stainless Steel, Nanjing University of Technology, Nanjing, China, 2009.

[8] M. F. Carlson, B. V. Narasimha Rao, and G. Thomas, "The effect of austenitizing temperature upon the microstructure and mechanical properties of experimental $\mathrm{Fe} / \mathrm{Cr} / \mathrm{C}$ steels," Metallurgical Transactions A, vol. 10, no. 9, pp. 1273-1284, 1979.

[9] H. Chai and C. Laird, "Mechanisms of cyclic softening and cyclic creep in low carbon steel," Materials Science and Engineering, vol. 93, no. C, pp. 159-174, 1987.

[10] Y. P. Chang, J. P. Yur, H. M. Chou, and H. M. Chu, “Triboelectrification mechanisms for self-mated carbon steels in dry severe wear process," Wear, vol. 260, no. 11-12, pp. 1209-1216, 2006.

[11] Y. P. Chang, H. M. Chu, and H. M. Chou, "Effects of mechanical properties on the tribo-electrification mechanisms of iron rubbing with carbon steels," Wear, vol. 262, no. 1-2, pp. 112-120, 2007.

[12] Y. P. Chang, Y. Y. Hung, L. M. Chu, J. P. Yur, and C. H. Lin, "The surface magnetization approach on assessing tribological properties of steels with different TiN coatings," Proceedings of the Institution of Mechanical Engineers J, vol. 223, no. 4, pp. 715$722,2009$.

[13] Y. P. Chang, J. H. Horng, J. P. Yur, L.-M. Chu, and Y.-C. Hwang, "The surface magnetization approach on assessing the tribological properties of iron sliding against iron coated with pure tin and with a tin composite," Proceedings of the Institution of Mechanical Engineers J, vol. 225, no. 12, pp. 1199-1208, 2011. 

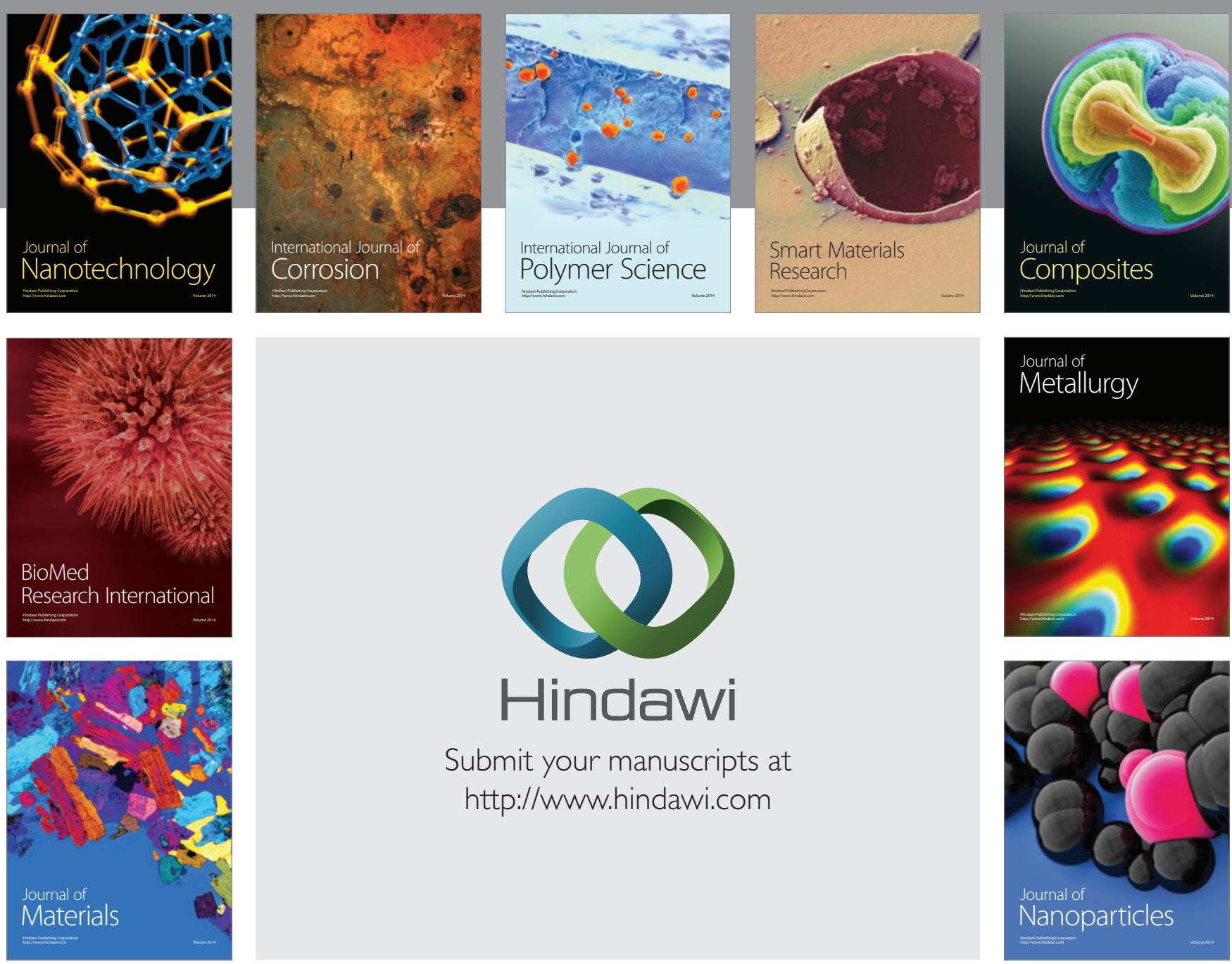

Submit your manuscripts at http://www.hindawi.com
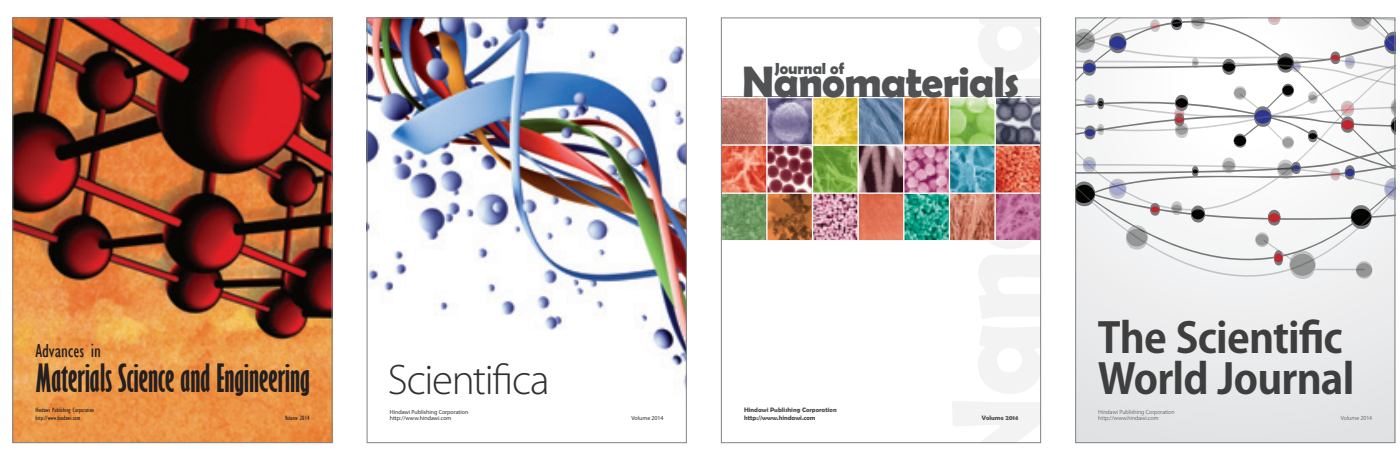

\section{The Scientific World Journal}
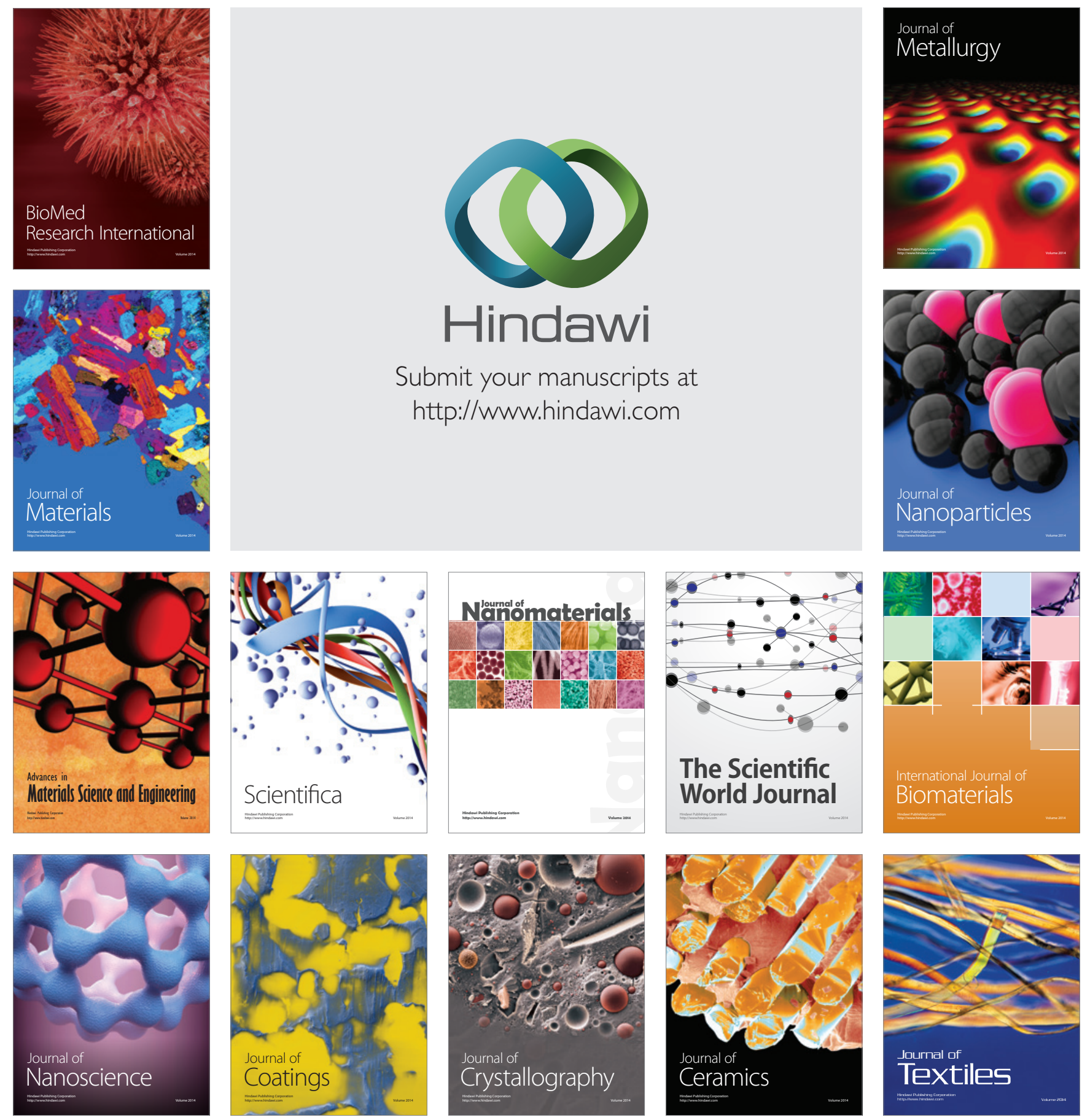